\title{
Alma Tallán: recuperando tradiciones a través de la organización comunitaria
}

El origen de Alma Tallán fue un proyecto de investigación. Entre otros logros sociales, Alma Tallán se ha convertido en una marca de empresa. Una actividad económica basada en el rescate de la tradición del tejido del sombrero de paja toquilla de Catacaos revalorando su uso en la vida cotidiana. Alma Tallán reconoce la importancia de esta tradición artesanal para la identidad cultural y el patrimonio cultural de la zona: Ias comunidades alrededor del sitio arqueológico de Narihualá en Catacaos, Piura (Perú). Lo más destacable es la labor dinamizadora de la población llevada a cabo para la consecución de este proyecto, un ejemplo de transmisión intergeneracional y de gestión cultural protagonizada por los habitantes.

Diana Anuska Aguirre Manrique | gestora cultural

URL de la contribución <www.iaph.es/revistaph/index.php/revistaph/article/view/4124>

A partir de mi investigación sobre los sombreros de paja toquilla en el distrito de Catacaos (2006 y 2012), pude conocer el entorno socioeconómico y cultural de los pobladores dedicados a esta práctica artesanal. En 2013, fruto de esta investigación se publicó el libro El sombrero de Catacaos. Tejiendo su historia y se declaró al sombrero de Catacaos como patrimonio de la nación.

\section{El contexto}

Catacaos está ubicado a $12 \mathrm{~km}$, al sureste de la ciudad de Piura, en el norte del Perú. Los sombreros cataquenses gozaron de fama mundial, hecho que está plenamente documentado y que sitúa a este distrito en el boom sombrerero internacional (finales del siglo XIX hasta mediados del siglo XX). De los conglomerados de tejedoras de sombreros, escogí a la comunidad La Campiña de Narihualá como el centro de operaciones del proyecto Alma Tallán, porque las familias basan su economía en la venta de los productos de paja toquilla y por las características de su población.

\section{La experiencia}

Diseñé el proyecto Alma Tallán: recuperación de tradiciones culturales y formador de formadores en los centros poblados aledaños al Sitio arqueológico de Narihualá Catacaos-Piura-Perú para participar en la convocatoria anual de Proyectos Culturales del BID, resultando ganador para ser financiado. Se ejecutó de julio a diciem- bre de 2013, teniendo como institución gestora a la Universidad de Piura (UDEP); y a otras entidades locales, como socias estratégicas. El proyecto implementó dos programas de fortalecimiento de capacidades: uno dirigido a las artesanas mayores para perfeccionar su técnica de tejido fino; y el otro, a las personas jóvenes tejedoras para formarlas como animadoras socioculturales, con la clara misión de motivar el interés de otros jóvenes y niños de la comunidad, por la recuperación de sus tradiciones.

En 2015 surgió una nueva versión del proyecto con un enfoque interdisciplinar que permitió la participación de voluntarios de diversas facultades. Un fruto importante de esta etapa fue el concurso de tejido de sombreros para niños "Tejiendo el futuro". En 2016, con bases más sólidas, Alma Tallán fortaleció sus objetivos hacia el desarrollo de capacidades para mejorar la identidad, el emprendimiento y las habilidades sociales. Las actividades se planificaron en dos fases. La primera fue imprescindible para el trabajo conjunto entre los voluntarios universitarios y los jóvenes de la comunidad, tanto para el desarrollo de habilidades como para la co-planificación de las actividades porque el proyecto se basa en el criterio de entre iguales donde todos aportan y aprenden.

Los voluntarios formados serían los responsables de las actividades posteriores. 


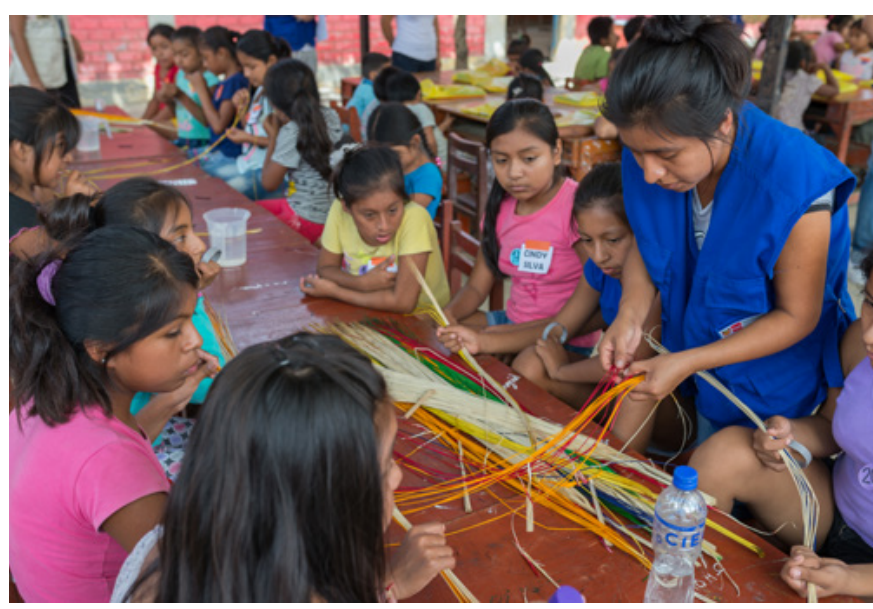

Taller:" Aprendiendo a tejer" | fotos Miguel Arreátegui

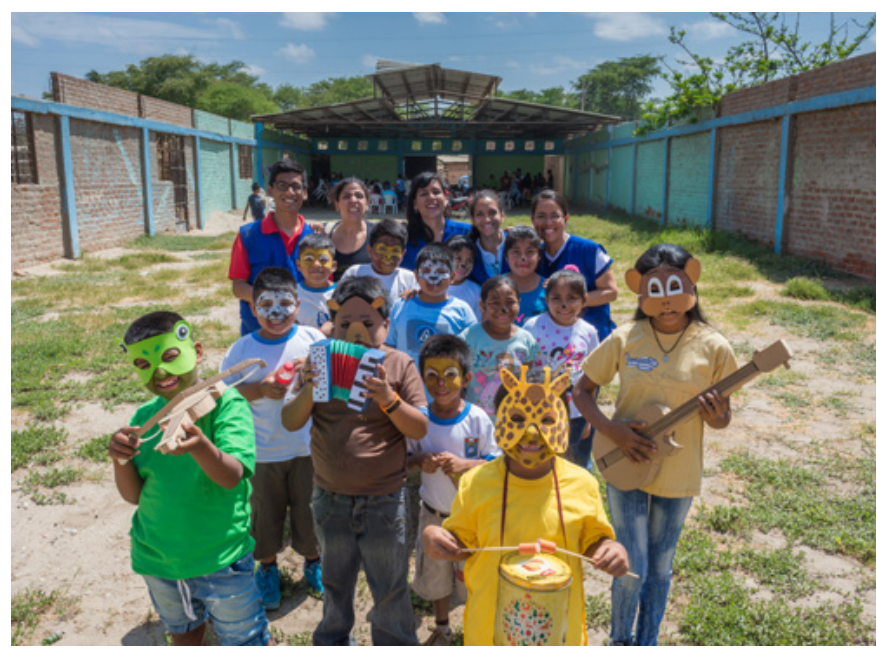

Festival "Alma Tallán"

En la segunda fase se implementó la escuela Alma Tallán, espacio donde los colores, plumones, témperas, plastilina y la paja toquilla fueron la base de los talleres que buscaron descubrir a los niños el valor de sus tradiciones culturales. La propuesta se complementó con los talleres "Alma Fotera" (fotografía) "La Voz de la Campiña" (radio), "Familia Tallán" (alfabetización y registro de tradiciones) y "Emprende Tallán" (empresa cultural) que buscaron desarrollar diversas habilidades en los participantes.

\section{Resultados}

Cada año, alrededor de 600 niños y niñas han podido disfrutar de los talleres. Gracias a su participación en

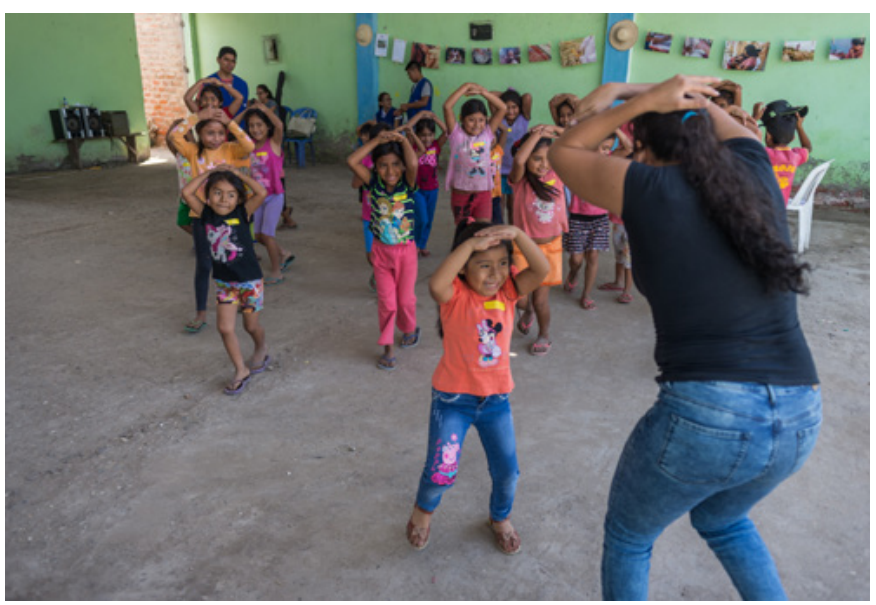

Taller: "Yo amo la música"

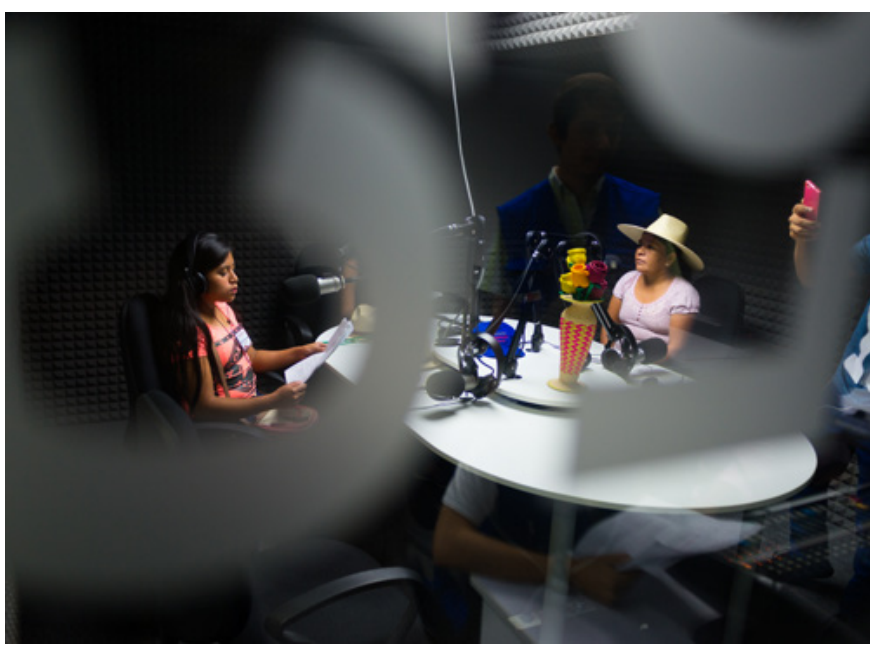

Taller de radio: "La Voz de La Campiña"

ellos han mejorado su desenvolvimiento personal y su percepción de los valores identitarios. Cerca de 30 jóvenes fueron formados como animadores socioculturales y se convirtieron en defensores del patrimonio local, siendo reconocidos como tal por el Ministerio de Cultura; sin embargo, las motivaciones para salir adelante y la mejora del sentimiento de orgullo fueron los principales logros.

Las familias de las artesanas integrantes de la Asociación Virgen del Pilar (aproximadamente 300 personas) han elevado su autoestima al sentir el aprecio y reconocimiento por su labor. Además, han interiorizado el valor cultural de su arte. 
En 2016, este proyecto fue ganador del Premio Nacional al Voluntariado Universitario y en 2017, todo el equipo tuvo una participación destacada en las labores de emergencia durante el fenómeno el Niño Costero, que ocasionó una inundación devastadora en la zona. Esto nos dio la oportunidad de diseñar programas especiales de apoyo, uno de ellos fue la "Tienda Vivencial: tejiendo el futuro" que, gracias a la empresa privada Grupo Centenario, se ha convertido el el primer espacio de comercialización de esta artesanía en la ciudad, que permite no solo comprar sino conocer y valorar a estas comunidades artesanas.

\section{Colofón}

La animación sociocultural como herramienta de la gestión cultural permite una acción transformadora de la comunidad, por eso nos propusimos utilizarla en este proyecto. Alma Tallán, en honor a su denominación "alma", busca animar a la comunidad en la consecución de su desarrollo fortaleciendo la participación. Se trata de un proceso lento que, de continuarse, concretará el gran objetivo de tener una comunidad identificada con su cultura, emprendedora y creativa, con herramientas para encaminarse hacia un desarrollo sostenible.

\section{BIBLIOGRAFÍA}

- ANDER-EGG, E. (2002) La práctica de la animación sociocultural y el léxico del animador. Lima, Perú: Fondo Ed. Pontificia Universidad Católica del Perú, 2002

- LOZANO ESCOBAR, J. O. (2014) La vieja nueva gestión cultural y sus vínculos con la animación sociocultural y la educación. En YAÑEZ CANAL, C. (coord.) Emergencias de la gestión cultural en América Latina. Bogotá: Universidad Nacional de Colombia, 2014, pp. 84-109

- MERINO FERNÁNDEZ, J. V. (1997) Programas de animación sociocultural: tres instrumentos para su diseño y evaluación. Madrid: Narcea Ediciones, 1997 